\title{
Chemical sputtering of carbon films by argon ions and molecular oxygen at cryogenic temperatures
}

\author{
C. Hopf*, M. Schlüter, and W. Jacob \\ Max-Planck-Institut für Plasmaphysik, EURATOM Association, Boltzmannstr. 2, 85748 Garching, Germany
}

\begin{abstract}
The experiments demonstrate the existence of a synergistic interaction of molecular oxygen and energetic ions with amorphous carbon leading to enhanced erosion; although the samples, amorphous hydrogenated carbon films, are not gasified by $\mathrm{O}_{2}$ at room temperature, additional ion bombardment at the same temperature leads to erosion rates that drastically exceed those of physical sputtering. Investigation of the temperature dependence from 400 down to $113 \mathrm{~K}$ shows that the erosion rate increases with decreasing temperature.
\end{abstract}

PACS numbers: 79.20.Rf, 82.65.+r, 81.65.Cf, 52.40.Hf

Published in Applied Physics Letters: Received 13 April 2007

Accepted for publication 9 May 2007

Published 1 June 2007

Appl. Phys. Lett. 90 (2007) 224106

Exposure to an oxygen plasma is a standard approach for the etching of carbon-based thin films which provides high rates. Examples of applications are patterning processes in microelectronics fabrication [1-3], the removal of diffusionbarrier carbon coatings on polyethylene terephthalate bottles prior to recycling [4], and the cleaning of optical components in synchrotron beamlines [5]. More recently it has also attracted considerable attention for the removal of redeposited hydrocarbon films in magnetic-confinement nuclear fusion experiments [6-12].

In the etching process, $\mathrm{CO}, \mathrm{CO}_{2}$, as well as-in case of hydrogen in the film- $-\mathrm{H}_{2} \mathrm{O}$ and $\mathrm{H}_{2}$ are formed as volatile erosion products [13]. The underlying microscopic mechanisms leading to the formation of these volatile species are manifold, as the surface is bombarded by a combination of neutral $\mathrm{O}_{2}$ and oxygen ions $\left(\mathrm{O}^{+}, \mathrm{O}_{2}^{+}, \mathrm{O}_{3}^{+}\right)$, as well as the radical species $\mathrm{O}$ and $\mathrm{O}_{3}$.

Neutral oxygen molecules alone lead to combustion of carbon at elevated temperatures. For amorphous hydrocarbon films (a-C:H), combustion starts above 500-600 K [14, 15]. The thermal oxygen radicals, atomic oxygen [16] and ozone [17], exhibit much higher reactivity at moderate temperatures, and there is indication that their reactivity toward a-C:H is still significant at room temperature. Bombardment of carbon with an oxygen ion beam leads to what is known as chemical sputtering or reactive ion etching [18-20]; in addition to physical sputtering the ions react chemically at the end of their range and form $\mathrm{CO}, \mathrm{CO}_{2}$, and $\mathrm{H}_{2} \mathrm{O}$, leading to highly enhanced sputtering yields and significantly lower threshold energies.

In the case of an oxygen plasma, where all the mentioned species impinge simultaneously on the film surface, mutual interactions between these species are to be expected. Such synergistic interactions are also known from other systems such as silicon etching in fluorine-containing plasmas [21] or the etching of a-C:H by thermal atomic hydrogen plus noble gas ion bombardment [22, 23]. Landkammer et al. [24]

*Corresponding author, e-mail: Christian.Hopf@ipp.mpg.de and Jacob et al. [7] have investigated the erosion of a-C:H in oxygen electron-cyclotron-resonance plasmas. The erosion rate shows a weak temperature dependence and increases strongly with ion energy. These two dependences make it clear that both thermally activated chemical reactions and ioncollisional effects play a role. Concerning the latter it was shown by using different mixtures of noble gases and oxygen for the plasma that it does not principally matter which ion species produces the damage [13]. In summary, Landkammer [13] concluded that the dominant mechanism of oxygen plasma erosion is a two step process in which ion bombardment induces defects at which thermal oxygen species can chemically react to form $\mathrm{H}_{2} \mathrm{O}, \mathrm{CO}$, or $\mathrm{CO}_{2}$.

The question thus arises whether thermal molecular oxygen contributes to this synergistic erosion or if the more reactive but usually less abundant $\mathrm{O}$ or $\mathrm{O}_{3}$ are required. To answer this question, we have studied the erosion of a-C:H by combined bombardment with thermal, molecular oxygen and chemically nonreactive $\mathrm{Ar}^{+}$ions with energies of 50 and $400 \mathrm{eV}$, respectively.

The experiments were performed in the setup MAJESTIX, which is described in detail in [25]. A hard a-C:H film is deposited on a silicon substrate in a preparation chamber and then transferred in vacuo to the experiment chamber. A massselected $\mathrm{Ar}^{+}$ion beam is produced by an ion gun and focused on the center of the sample. Molecular oxygen is supplied to the chamber by a constant gas flow while the chamber is continuously pumped. The $\mathrm{O}_{2}$ flux density onto the substrate is calculated from the resulting oxygen partial pressure. Variation of the pressure is achieved by varying the $\mathrm{O}_{2}$ flow with a pressure-controlled thermovalve. The temperature of the substrate is controlled by either heating the substrate resistively, cooling the whole substrate holder with cold nitrogen gas, or both simultaneously. The temperature is measured with a thermocouple on the sample surface. In cooling mode, temperatures down to $\approx 110 \mathrm{~K}$ are feasible. Time-resolved measurement of the film thickness is achieved by in situ ellipsometry. This sensitive technique allows to measure film thickness changes of below one monolayer and rates of less than $10^{10} \mathrm{C}$ atoms $\mathrm{cm}^{-2} \mathrm{~s}^{-1}, \approx 10^{-6} \mathrm{~nm} / \mathrm{s}$.

Figure 1 shows the erosion yield, i. e., the number of car- 


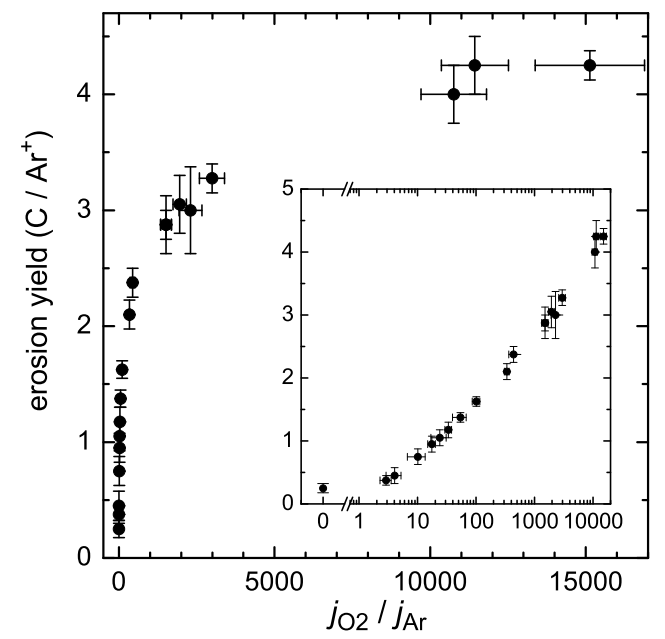

FIG. 1: Dependence of the erosion yield (removed $\mathrm{C}$ per incident $\mathrm{Ar}^{+}$) on the ratio $j_{\mathrm{O}_{2}} / j_{\mathrm{Ar}^{+}}$at a sample temperature of $300 \mathrm{~K}$. The ion energy was $400 \mathrm{eV}$ and the ion flux density was constant at $4 \times$ $10^{12} \mathrm{~cm}^{-2} \mathrm{~s}^{-1}$.

bon atoms removed per incident $\mathrm{Ar}^{+}$ion, as a function of the neutral-to-ion flux ratio $j_{\mathrm{O}_{2}} / j_{\mathrm{Ar}^{+}}$. The ion energy is $400 \mathrm{eV}$ and the ion flux density is constant at $4 \times 10^{12} \mathrm{~cm}^{-2} \mathrm{~s}^{-1}$ while the flux density of oxygen is varied. The sample temperature is $300 \mathrm{~K}$. At $j_{\mathrm{O}_{2}} / j_{\mathrm{Ar}^{+}}=0$, erosion is entirely driven by physical sputtering with a yield of 0.25 . As soon as a certain $\mathrm{O}_{2}$ flux is added, the erosion rate begins to increase rapidly. At $j_{\mathrm{O}_{2}} / j_{\mathrm{Ar}^{+}}=4$, the yield is already 0.45 , and at the highest investigated flux ratio of $1.14 \times 10^{4}$, the yield reaches more than four removed carbon atoms per ion. For comparison, the maximum physical sputtering yield of hard a-C:H under $\mathrm{Ar}^{+}$ bombardment is $\approx 1.2$ at $15 \mathrm{keV}$, as predicted by TRIM.SP [26] simulations. The linear presentation of the data in Fig. 1 shows a slower rise of the yield with increasing flux ratio, indicating that the ion flux starts limiting the erosion rate.

The observed enhancement of the erosion rate over physical sputtering in the presence of molecular oxygen is a clear indication that the oxygen molecules react chemically with the surface if it is bombarded by ions. The involvement of chemical reactions makes an investigation of the temperature dependence very desirable. At elevated temperatures, $\mathrm{O}_{2}$ is known to oxidize and gasify a-C:H without the involvement of ion bombardment. It therefore seems especially interesting to investigate the synergistic erosion process below room temperature.

Figure 2 shows temperature-dependent erosion yields at two different ion energies of 50 and $400 \mathrm{eV}$ and at a constant flux ratio of $\mathrm{j}_{2} / j_{\mathrm{Ar}^{+}} \approx 3000$. Surprisingly, the yield increases toward lower temperatures in the whole investigated range from 415 to $113 \mathrm{~K}$. Additionally, the yields at the higher ion energy are higher, which can be ascribed to the more effective damage production.

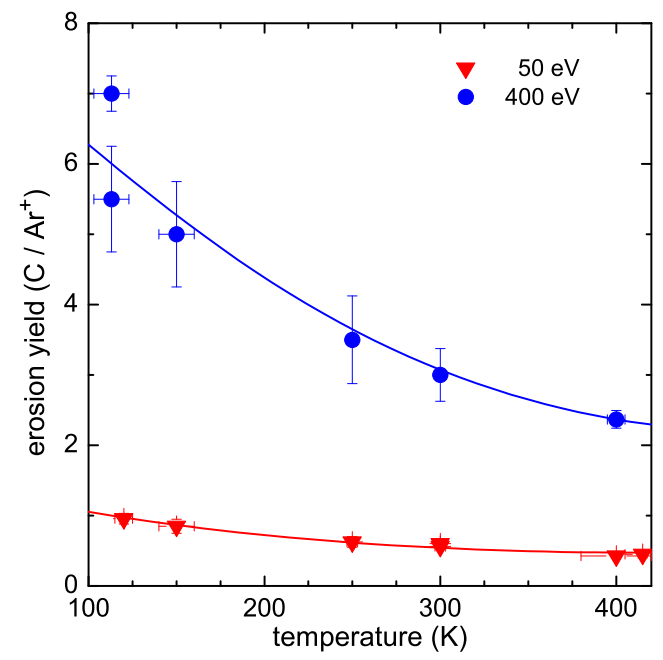

FIG. 2: Dependence of the erosion yield (removed $\mathrm{C}$ per incident $\mathrm{Ar}^{+}$) on surface temperature. The ion and $\mathrm{O}_{2}$ flux densities were constant at $4 \times 10^{12}$ and $1.1 \times 10^{16} \mathrm{~cm}^{-2} \mathrm{~s}^{-1}$, respectively. The lines are guides to the eyes.

The existence of the ion $/ \mathrm{O}_{2}$ synergism in the erosion of carbon materials was proven earlier by Vietzke et al. [27], who investigated graphite erosion under $5 \mathrm{keV} \mathrm{Ar}{ }^{+}$ion bombardment in a background of thermal oxygen. A quadrupole mass spectrometer was used to detect the released species and showed $\mathrm{CO}$ production in the whole investigated temperature range between 300 and $1500 \mathrm{~K}$. In an analogous fashion to our experiments, the $\mathrm{CO}$ signal increased with decreasing temperature between 800 and $300 \mathrm{~K}$. The difference in the temperature below which the increase is observed might be due to the different sample materials, a-C:H and graphite, respectively.

The observed synergism recalls another synergism in a-C:H erosion, namely, that between ion bombardment and atomic hydrogen [22, 23, 28-30]. In this case, the proposed explanation [23] was that ion bombardment creates dangling bonds at and below the surface which become passivated by $\mathrm{H}$. By repeated such events hydrocarbon molecules are formed which leave the surface. In principle the synergism between ions and $\mathrm{O}_{2}$ could be explained by a similar mechanism. It is worth noting, however, that, whereas in the hydrogen case the atomic radical is required, in the oxygen case the $\mathrm{O}_{2}$ molecule provides sufficient reactivity. The mechanism in the hydrogen-plus-ions case, however, hardly provides an explanation for the low-temperature enhancement, and indeed no such increased erosion at low temperature was found in corresponding experiments with $\mathrm{Ar}^{+} / \mathrm{H}$ [31].

A similar increase of the erosion rate with decreasing temperature was found for the chemical sputtering of silicon with noble gas ions and fluorine species [32, 33]. A difference compared with our case is, however, that here the chemically reactive precursor, either $\mathrm{F}$ atoms or $\mathrm{XeF}_{2}$, leads 
to spontaneous etching (without ion bombardment) already below room temperature. While the spontaneous etch rate due to $\mathrm{F}$ atoms decreases in the temperature range from 300 to $77 \mathrm{~K}$ [32], it increases below $300 \mathrm{~K}$ in the case of $\mathrm{XeF}_{2}$. The temperature dependence below approximately $300 \mathrm{~K}$ for both chemical sputtering with $\mathrm{Ar}^{+} / \mathrm{XeF}_{2}$ and spontaneous etching with $\mathrm{XeF}_{2}$ was explained in terms of a temperature-dependent steady state physisorbed $\mathrm{XeF}_{2}$ coverage [34, 35]; increasing temperature leads to an increasing desorption rate of $\mathrm{XeF}_{2}$ which is bound to the surface with $\approx 0.03 \mathrm{eV}$. The rate of the ion-induced chemical erosion reaction is proportional to the $\mathrm{XeF}_{2}$ coverage and hence decreases with increasing temperature.

It seems reasonable to assume a similar mechanism for chemical sputtering of a-C:H by $\mathrm{Ar}^{+} / \mathrm{O}_{2}$ : Oxygen molecules adsorb at the surface without a barrier and thus with a temperature-independent rate. This adsorption is counteracted by thermal desorption, hence leading to a decreasing oxygen coverage of the surface with increasing $T$. Ion bombardment induces reactions between the adsorbed oxygen species and the a-C:H film whereby volatile carbon oxides and water are formed. The rate increases with ion energy due to increasing damage production and with increasing oxygen flux density due to a shift of the steady state coverage toward higher coverages, thus qualitatively explaining the experimentally observed energy and flux dependence. It should be noted that this mechanism implies that the erosion yield depends explicitly on the oxygen flux density and not only on the flux ratio.

In summary, we have unambiguously observed a synergism between thermal oxygen molecules and energetic $\mathrm{Ar}^{+}$ ions in the erosion of a-C:H films; while $\mathrm{O}_{2}$ alone does not erode $\mathrm{a}-\mathrm{C}: \mathrm{H}$ in the investigated temperature range, its presence during $\mathrm{Ar}^{+}$ion bombardment leads to an enhancement of the sputtering rate of more than an order of magnitude compared to physical sputtering. The erosion yield was found to increase with the neutral-to-ion flux ratio as well as with ion energy. Temperature-dependent measurements revealed that the yield increases with decreasing temperature in the range of $400-110 \mathrm{~K}$. A reasonable explanation for this phenomenon is the buildup of a temperature-dependent oxygen coverage as a precursor for ion-induced volatile oxide formation.
[1] W. I. Urruchi, M. Massi, H. S. Maciel, C. Otani, and L. N. Nishioka, Diamond Relat. Mater. 9, 685 (2000).

[2] M. Massi, R. D. Mansano, H. S. Maciel, C. Otani, P. Verdonck, and L. N. B. M. Nishioka, Thin Solid Films 343-344, 381 (1999).

[3] S. Steudel, K. Myny, S. De Vusser, J. Genoe, and P. Heremans, Appl. Phys. Lett. 89, 183503 (2006).

[4] K. K. Hirakuri, K. Kuwashima, K. Tatsuta, and K. Sato, Diamond Relat. Mater. 14, 1067 (2005).

[5] F. Eggenstein, F. Senf, T. Zeschke, and W. Gudat, Nucl. Instrum. Meth. A 467, 325 (2001).

[6] W. L. Hsu, J. Vac. Sci. Technol. A 7, 1047 (1989).

[7] W. Jacob, B. Landkammer, and C. Wu, J. Nucl. Mater. 266-269, 552 (1999).

[8] D. Mueller, W. Blanchard, J. Collins, J. Hosea, J. Kamperschroer, P. H. LaMarche, A. Nagy, D. K. Owens, and C. H. Skinner, J. Nucl. Mater. 241-243, 897 (1997).

[9] J. S. Hu, J. G. Li, X. M. Wang, and the HT-7 team, Plasma Phys. Control. Fusion 47, 1271 (2005).

[10] J. S. Hu, J. G. Li, and X. M. Wang, J. Nucl. Mater. 350, 9 (2006).

[11] G. Counsell, P. Coad, C. Grisola, C. Hopf, W. Jacob, A. Kirschner, A. Kreter, K. Krieger, J. Likonen, V. Philipps, et al., Plasma Phys. Control. Fusion 48, B189 (2006).

[12] C. Hopf, V. Rohde, W. Jacob, A. Herrmann, R. Neu, J. Roth, and ASDEX Upgrade Team, J. Nucl. Mater. 363-365, 882 (2007).

[13] B. Landkammer, Phd thesis, Universität Bayreuth (1999).

[14] W. M. Wang, W. Jacob, and J. Roth, J. Nucl. Mater. 245, 66 (1997).

[15] K. Maruyama, W. Jacob, and J. Roth, J. Nucl. Mater. 264, 56 (1999).

[16] D. E. Rosner and H. D. Allendorf, Kinetics of the attack of refractory materials by dissociated gases (Plenum Press, New York, 1970).

[17] R. Moormann, S. Alberici, H.-K. Hinssen, and C. H. Wu, Fus. Eng. Des. 49-50, 295 (2000).
[18] E. Hechtl, J. Bohdansky, and J. Roth, J. Nucl. Mater. 103, 333 (1981).

[19] E. Hechtl, J. Bohdansky, and J. Roth, J. Nucl. Mater 123, 1431 (1984).

[20] A. Refke, V. Philipps, E. Vietzke, M. Erdweg, and J. von Seggern, J. Nucl. Mater. 212-215, 1255 (1994).

[21] J. W. Coburn and H. F. Winters, J. Appl. Phys. 50, 3189 (1979).

[22] C. Hopf, A. von Keudell, and W. Jacob, Nucl. Fusion 42, L27 (2002).

[23] C. Hopf, A. von Keudell, and W. Jacob, J. Appl. Phys. 94, 2373 (2003).

[24] B. Landkammer, A. von Keudell, and W. Jacob, J. Nucl. Mater. 264, 48 (1999).

[25] W. Jacob, C. Hopf, A. von Keudell, M. Meier, and T. SchwarzSelinger, Rev. Sci. Instrum. 74, 5123 (2003).

[26] W. Eckstein, Computer simulation of ion-solid interactions, vol. 10 of Springer Series in Materials Science (Springer Verlag, Berlin and Heidelberg, 1991), 1st ed.

[27] E. Vietzke, T. Tanabe, V. Philipps, M. Erdweg, and K. Flaskamp, J. Nucl. Mater. 145-147, 425 (1987).

[28] E. Vietzke and A. A. Haasz, in Physical Processes of the Interaction of Fusion Plasmas with Solids, edited by W. O. Hofer and J. Roth (Academic Press, 1996), pp. 135-176.

[29] E. Vietzke, K. Flaskamp, and V. Philipps, J. Nucl. Mater. 111112, 763 (1982).

[30] A. A. Haasz, O. Auciello, P. C. Stangeby, and I. S. Youle, J. Nucl. Mater. 128-129, 593 (1984).

[31] M. Schlüter, C. Hopf, and W. Jacob (2007), to be published.

[32] C. B. Mullins and J. W. Coburn, J. Appl. Phys. 76, 7562 (1994).

[33] M. J. M. Vugts, L. J. F. Hermans, and H. C. W. Beijerinck, J. Vac. Sci Technol. A 14, 2820 (1996).

[34] P. G. M. Sebel, L. J. F. Hermans, and H. C. W. Beijerinck, J. Vac. Sci. Technol. A 18, 2759 (2000).

[35] M. J. M. Vugts, G. L. J. Verschueren, M. F. A. Eurligs, L. J. F. Hermans, and H. C. W. Beijerinck, J. Vac. CSci. Technol. A 14, 2766 (1996). 